\title{
Letter to the editor: Strengthening epidemiological surveillance of Neisseria gonorrhoea - beyond the detection of cases
}

Victoria Hernando ${ }^{1}$, Alicia Magistris ${ }^{2}$, Antonio Nicolau ${ }^{3}$, Susana Ramón ${ }^{4}$, Carmen Varela ${ }^{1}$, Marta Ruiz-Algueró ${ }^{1}$, Asunción Diaz $^{1}$

1. HIV Surveillance and Behavioral Monitoring Unit, National Center of Epidemiology, Carlos III Institute of Health, Madrid, Spain

2. Epidemiology Unit, Insular Center Ibiza-Formentera, Consejería de Salud, Balearic Islands, Spain

3. Epidemiology Service, Consejería de Salud, Balearic Islands, Spain

4. Microbiology Laboratory, Can Misses Hospital, IBSALUT, Ibiza, Balearic Islands, Spain

Correspondence: Victoria Hernando (vhernando@isciii.es)

Hernando Victoria, Magistris Alicia, Nicolau Antonio, Ramón Susana, Varela Carmen, Ruiz-Algueró Marta, Diaz Asunción. Letter to the editor: Strengthening

epidemiological surveillance of Neisseria gonorrhoea - beyond the detection of cases. Euro Surveill. 2019;24(25):pii=1900355. https://doi.org/10.2807/1560-7917.

ES.2019.24.25.1900355

To the editor: We have read the interesting article by Eyre DW et al. describing a Neisseria gonorrhoea (NG) FC428 clone detected in two female cases who developed infection following contact with United Kingdom (UK)-resident men linked to travel to Ibiza, Spain. These cases provide evidence that the $\mathrm{FC}_{42} 8$ clone's transmission is occurring within Europe. The widespread distribution of this clone threatens the effectiveness of gonorrhoea treatment [1].

As both cases had contact with the same sexual network in Ibiza, an exhaustive search of other probable NG cases was developed by the national and local public health authorities. During 2018, 82 cases of gonorrhoea were diagnosed in Ibiza; 80\% $(n=66)$ were men with a median age of 29 years (interquartile range (IQR): $25-36)$ and $20 \%(n=16)$ were women with a median age of 32.5 years (IQR: 27.5-37.5). Forty percent of the cases $(n=33)$ were foreigners, but none of them were tourists. Among the foreigners, 26 were men, 20 were from Europe (half of which were from Italy) and 12 were from Latin America. The most common clinical presentation was urethritis among men (62/66) and cervicitis among women (15/16).

A positive culture was confirmed in $90 \%(n=74)$ of the cases; $91 \%(n=60 / 66)$ of cultures were positive among men and $87 \%(14 / 16)$ among women. Of the $82 \mathrm{NG}$ isolates tested, $26.8 \%$ showed resistance to penicillin (intermediate susceptibility), $2.4 \%$ to ciprofloxacin and $11 \%$ to both antibiotics. Resistance to ciprofloxacin and levofloxacin was found in $11 \%(n=9)$ of isolated strains, and $15.8 \%(n=13)$ showed additional resistance to penicillin. Two strains showed resistance to ciprofloxacin, levofloxacin and cefuroxime. None of the isolated and tested strains showed resistance to ceftriaxone. In Ibiza there are two hospitals, one public and one private. The notification of gonococcal cases are compulsory in both hospitals. No positive cases were diagnosed in the private hospital in 2018, and all previously described cases were diagnosed in the public hospital.

The incidence rate of gonococcal infection has increased in Spain since 2001. From 2001-13, the annual change was $11.7 \%$ (95\% confidence interval (Cl): $9.6-13.9)$ and from $2013-17$ it was $26.3 \%$ (95\% Cl: 20.7-32.2). In 2017, the Balearic Islands had one of the highest incidence rates in Spain, with 41.79 cases per 100,000 population [2].

In 2011, the first two cases of ceftriaxone-resistant NG were reported in Catalonia, Spain. Both cases were men who have sex with men (MSM). One of the cases was diagnosed with urethral discharge by a general practitioner. He was treated with $100 \mathrm{mg}$ of doxycycline twice a day for 7 days. The other case was his partner and was asymptomatic, with no signs of proctitis or urethritis. He was treated with levofloxacin for 7 days. In both cases, ceftriaxone-resistant NG strains were isolated [3]; these were the third and fourth ceftriaxone-resistant NG strains isolated in Europe and were genetically related to the strain isolated in France [4]. As all cases were MSM, there is strong indication that resistance clones may circulate in this community.

Spain is one of the participating countries in the European Gonococcal Antimicrobial Surveillance Programme (Euro-GASP) [5]. In its last report, published in 2018, cefixime resistance was isolated from $1.6 \%$ of the 365 tested isolates submitted from Spain, but no ceftriaxone resistance was identified. Nevertheless, it is necessary to anticipate an emergency situation in which treatment of NG infection can 
fail. International travel and new technologies such as social media and dating apps can contribute to the spread of new resistance strains that can compromise NG treatment effectiveness. It is therefore important that we reinforce communication among the countries that are facing this global challenge. At the national level, a multidisciplinary approach is needed, so clinicians, microbiologists, epidemiologists and public health authorities should be involved. Spain has developed a national plan against antimicrobial resistance that includes gonococcal infection as a global threat. One of the milestones of this plan is to reinforce the surveillance and control of antimicrobial resistance.

\section{Acknowledgements}

We would like to acknowledge Maribel Medina, Microbiology Laboratory of Policlínica Nuestra Señora del Rosario, Ibiza.

\section{Conflict of interest}

None declared.

\section{Authors' contributions}

VH wrote the first draft of the manuscript. VH, MR, CV and AD formed part of the outbreak research team of sexually transmitted infections. AM, AN and SR formed part of outbreak research team in the Balearic Islands. All authors reviewed the final version of the manuscript.

\section{References}

1. Eyre DW, Town K, Street T, Barker L, Sanderson N, Cole MJ, et al. Detection in the United Kingdom of the Neisseria gonorrhoeae $\mathrm{FC} 428$ clone, with ceftriaxone resistance and intermediate resistance to azithromycin, October to December 2018. Euro Surveill. 2019;24(10):1900147. https:// doi.org/10.2807/1560-7917.ES.2019.24.10.1900147 PMID: 30862336

2. Unidad de Vigilancia del VIH y conductas de riesgo [HIV Surveillance and Behavioral Monitoring Unit]. Vigilancia epidemiológica de las infecciones de transmisión sexual, 2017. [Epidemiological surveillance of Sexually Transmitted Infections in Spain, 2017]. Madrid: Centro Nacional de Epidemiología - Instituto de Salud Carlos III/Plan Nacional sobre el Sida-S.G. de Promoción de la Salud y Vigilancia en Salud Pública: 2019.Spanish. Available from: http://www. isciii.es/ISCIII/es/contenidos/fd-servicios-cientifico-tecnicos/ fd-vigilancias-alertas/fd-enfermedades/fd-sida/vigilancia-deconductas-de-riesgo-para-el-VIH.shtml

3. Cámara J, Serra J, Ayats J, Bastida T, Carnicer-Pont D, Andreu A, et al. Molecular characterization of two high-level ceftriaxoneresistant Neisseria gonorrhoeae isolates detected in Catalonia, Spain. J Antimicrob Chemother. 2012;67(8):1858-60. https:// doi.org/10.1093/jac/dks162 PMID: 22566592

4. Unemo M, Golparian D, Nicholas R, Ohnishi M, Gallay A, Sednaoui P. High-level cefixime- and ceftriaxone-resistant Neisseria gonorrhoeae in France: novel penA mosaic allele in a successful international clone causes treatment failure. Antimicrob Agents Chemother. 2012;56(3):1273-80. https:// doi.org/10.1128/AAC.05760-11 PMID: 22155830

5. European Centre for Disease Prevention and Control (ECDC) Gonococcal antimicrobial susceptibility surveillance in Europe. Stockholm: ECDC; 2018. Available from: https://ecdc.europa. eu/sites/portal/files/documents/EURO-GASP-report-2016.pdf
License, supplementary material and copyright

This is an open-access article distributed under the terms of the Creative Commons Attribution (CC BY 4.0) Licence. You may share and adapt the material, but must give appropriate credit to the source, provide a link to the licence and indicate if changes were made.

Any supplementary material referenced in the article can be found in the online version.

This article is copyright of the authors or their affiliated institutions, 2019. 